\title{
Students' Perception on Borobudur Temple as Mathematic Learning Resource
}

\author{
Sri Wulandari Danoebroto \\ PPPPTK Matematika, Sleman, Indonesia \\ wulan_aarf@yahoo.com
}

\begin{abstract}
This study aims to describe junior high school student's perception of Borobudur Temple as mathematic learning resources. Borobudur Temple is well known as having extraordinary architecture built algorithmically. The parts of Borobudur Temple such as the stupa, statue, and wall carvings (relief) consist of many geometric models. This study employs an ethnomathematics perspective in describing perceptions about cultural artefacts as a mathematical model. The result of this study may be used as a basis for developing meaningful mathematic learning in schools. The sample of the study was 313 students of junior high school located near Borobudur Temple. The measure of the sampling adequacy with $\mathrm{KMO}$ is 0.86 from which confirms that the number of the sample is sufficient. The data were collected using a questionnaire with Likert scale 1 to 4 with the following range: (1) disagree, (2) neutral, (3) agree, and (4) strongly agree. The exploratory factor analysis yielded three factors of perception of Borobudur Temple as a mathematic model, those are: (1) Borobudur Temple is a geometry model, (2) Borobudur Temple can be used as mathematic learning source at school, and (3) learning mathematics from Borobudur Temple is helpful for students. The total variance reached $49,572 \%$. The value of Cronbach alpha was 0,8204 for the 14 items. The data were analyzed using descriptive statistics to attain average items of mean and average standard deviation for each factor. The result of the research shows that: (1) students agree that Borobudur Temple is a geometry model, (2) Borobudur Temple can be used as mathematic learning source at school, and (3) learning mathematics from Borobudur Temple is helpful for them.
\end{abstract}

Keywords: Borobudur Temple, mathematics, perception, students

\section{Introduction}

Borobudur Temple belongs to Indonesian cultural heritage which is recognized worldwide. Many tourists come to visit the temple and admire the beauty of its architecture. Borobudur Temple has become a symbol of world civilization in the laboratory of history and architecture. However, Borobudur as a laboratory of mathematics education is not popular among people, only few of them know that Borobudur Temple is a very interesting mathematical object.

\section{Characteristic of Mathematics at Borobudur Temple Building}

Research by Situngkir (2010) found that Candi (temple) Borobudur was built algorithmically from which it applied fractal geometry and self-similarity. The essential building of Borobudur is a stupa, but not with a commonly stupa-shaped dome, instead it is a punden (holy place) with six levels of a square (Soetarno, 1988, p. 90). The temple consists of nine stacked platforms, six square and three circular, topped by a central dome. The temple is decorated with 2,672 relief panels and 504 Buddha statues. The central dome is surrounded by 72 Buddha statues, each seated inside a perforated stupa. All parts belong together, and overall 
it builds a stupa. The self-similarity of Borobudur Temple can be observed through the dimensionality of stupa (Situngkir, 2010, p. 1).

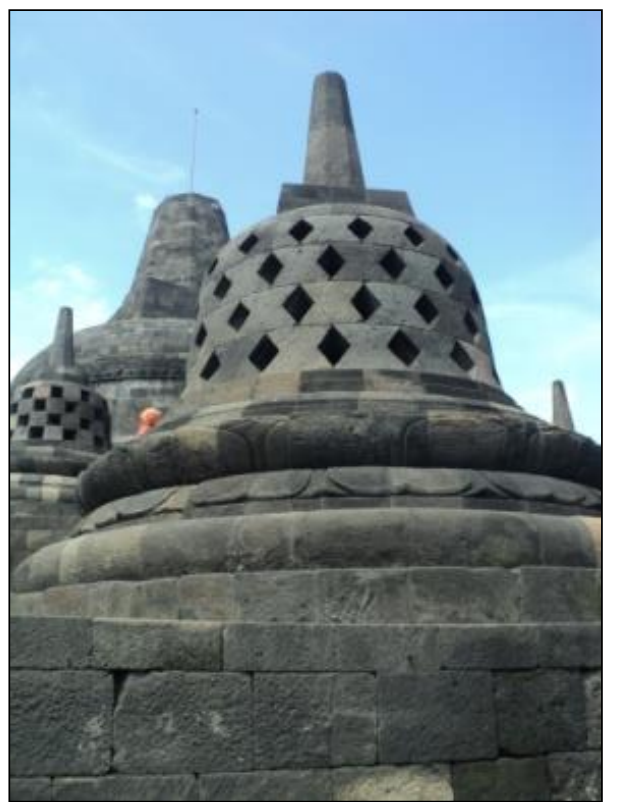

Figure 1. Stupa of Borobudur (source: private document)

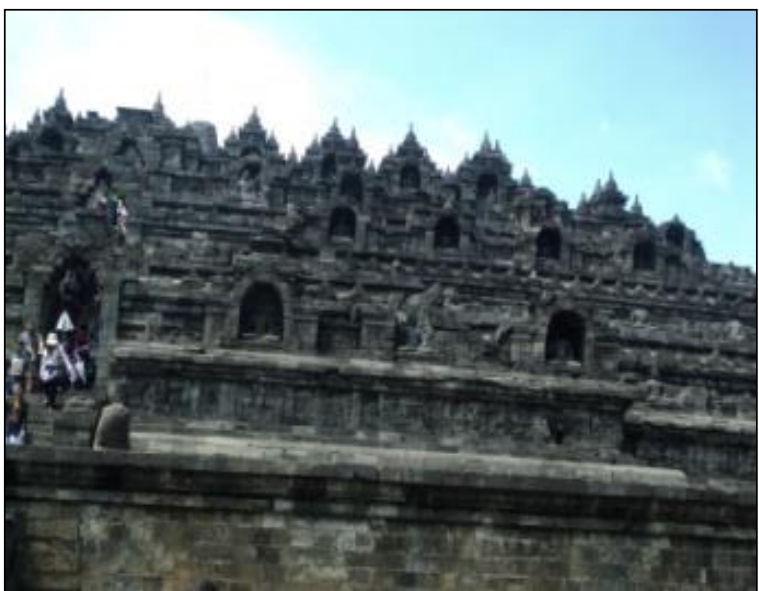

Figure 2. Self-similarity at Borobudur (source: private document)

In accordance to the presumption that Borobudur Temple was built during the $9^{\text {th }}$ century Sailendra dynasty of Buddhist Mahayana, the Borobudur stupa is seen as an imitation of the universe in relation to the philosophy of Buddhism. There are three parts to the Borobudur Temple as follows: (1) the foot of the temple called Kamadhatu signifying the natural state of the ordinary human being (the world of desire), (2) the parts consisting of four levels of a square called Rupadhatu as signifying the level of man after leaving all worldliness (the world of forms), and (3) the top in the form of three terraced plains including the stupa called Arupadhatu as signifying the level of the divine or nirvana (the world of formlessness) (Soetarno, 1988, p. 91). At the level of Rupadatu there are successively from the bottom to the top, 32, 24, and 16 or multiples of four piece stupas containing Buddha statues. 


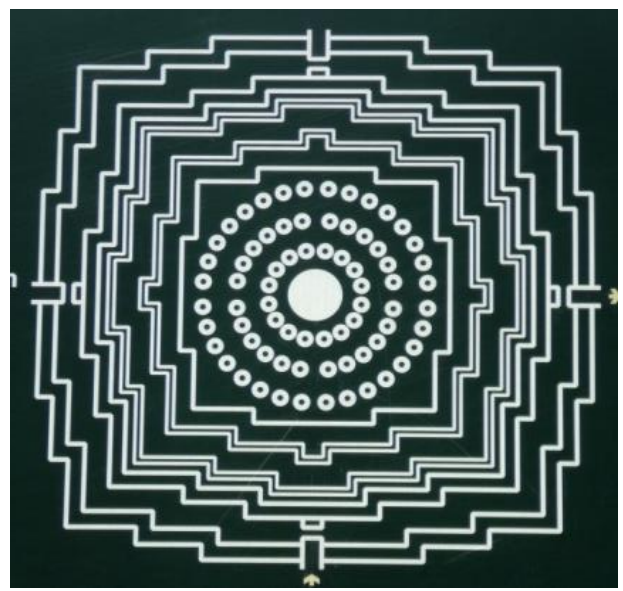

Figure 3. Sketch of Borobudur views from the top (source: private document)

Research by Parmono (1988) on the design principle at Borobudur Temple found patterns of regularity in the physical building of Borobudur Temple but did not find a standard unit of measurement for the design principle of it. He filed the temple' component ratio, although this ratio cannot be a reference to an overall ratio of building components. All the temple buildings in Java, including Borobudur, have a ratio of 4: 6: 9 which states a comparison of base or foundation of the building to the building height of the temple and to the temple roof height.

\section{The Ethnomathematics Perspective on Borobudur Temple}

The physical building of Borobudur Temple covers a giant geometry model with selfsimilarity and regularity shapes from its parts. This conclusion comes from a rigorous and continuous study of the experts. Free observation might come to the same conclusion that it is a mathematics object. Parts of Borobudur Temple are geometrical shapes such as cuboid (rectangular prisms), prisms, pyramids, trapezoids, and other interesting shapes that are unknown as to their mathematical terms.

Borobudur Temple is a cultural artefact which is embedded with the philosophical values. The study of mathematics that is embedded in culture is known as ethnomathematics. Ethnomathematics is derived from three terms ethno, mathema, and tics. Ethnomathematics is not only ethnic mathematics or mathematics that applies to a particular ethnic group, but ethno also includes all the cultural groups that can be identified with the jargon, codes, symbols, myths, and even specific ways in thinking and acting; then mathema is interpreted as knowledge and attitudes about space, time, measurement, grouping, comparison, quantity, and conclusions; and tic covers methods or techniques and codes that are received, distributed, transmitted, and spread by certain individuals or groups (Francois \& Van Kerkhove, 2010, p. 127). 
Mathematics in everyday situations could not be separated from its culture. The ideas and practices of mathematics are influenced by the values, norms, customs, and traditions prevailing in the society. For instance, ancient Javanese people used the metric system in the development process of Borobudur Temple, namely tala. The standard length measurement was defined as the length of a human face from the forehead's hairline to the tip of the chin or the distance from the tip of the thumb to the tip of the middle finger when both fingers are stretched at their maximum distance (Situngkir, 2010, p. 2). It was not universal and even varied among people. As is true for most societies it was the most feasible strategy to measure by using part of their body.

These ideas and thoughts were then arranged as a representation of concepts and manifested as artifacts, such as images, arts, and techniques (D'Ambrosio, 2006, p. 6). Finding the characteristics of mathematics inside an artefact was similar to looking for something hiding behind it. According to Gerdes (2014, p. 55), we have to try to reconstruct or unfreeze the frozen mathematics inside the artefact.

\section{Borobudur Temple as Mathematic Learning Resources at School}

The process of reconstructing or rediscovering the hidden mathematics inside Borobudur could be the starting points for doing and elaborating mathematics in the classroom. There are pedagogical values from using cultural artefact as mathematics learning resources through making the learning of mathematics more interesting. Besides, the most important benefit is the engagement of students with the objects.

Students are enabled to think and do mathematics by observing, investigating, and exploring the physical building of Borobudur Temple. For junior high school, mathematical topics might be the geometry of two-dimensional such as square, rectangular, trapezoid, and its properties studied. Students can investigate the pattern tiling in the walls and floors of the temple. The geometry of three-dimension such as cubes, cuboids, prisms, and trapezoids are common geometric shapes for students. At the Borobudur Temple, they can find uncommon three-dimensional shapes and study them. Students can practice measuring length, width, area, or volume of those objects and then compare their size. As well as geometry the students can also be challenged to find weather the number of stupas has a pattern in number.

The use of cultural artefact as mathematic learning resources at school is actually implementing a culturally relevant pedagogy. It will help students to develop their intellectual, social, emotional, and political learning because it is using their own cultural history to improve their competence (Rosa \& Orey, 2013, p. 74). Using objects from their culture to study directs them to meaningful learning. 


\section{Students' Perception and Their Intuition of Mathematics}

According to Tall (2013, p. 2), mathematics begins from perceptions of and actions on the natural world around us. Beginning with practical mathematics in the real world, students build their perception about shape and space. Actions with counting and measuring lead them to arithmetic operations and then symbolic algebra.

Practical mathematics in everyday situations may not be applying the formal mathematics. For example, students can distinguish simple or complex shape by using their intuition. When students deal with mathematics at school, they will turn the intuition of mathematics from everyday experiences with a mathematical concept into a more formal and standard mathematical form. Sometimes later on changes or substitutions may also occur between everyday experience and mathematical concepts that are connected and activated for a particular situation or context (Prediger, 2004, p. 384).

The connection between students' intuition and formal mathematics will emerge if the subject matter is related to something they already know. Mathematical knowledge is built on the knowledge of students from outside the school (Masingila, 1993, p. 19). It means that they have some experience with mathematics. The process of building formal mathematics from intuitive mathematics is an effort to construct knowledge that occurs within the students themselves supported by the socio-cultural environment. Furthermore, formal knowledge will rise for the students as their understanding grows of how mathematics is related to everyday life and culture.

Student's perception of how mathematics is used is a function of their views of mathematics (Masingila, 2002, p. 37). Most students think that mathematics is identical with school mathematics. Students also generally believe that learning mathematics is an isolated and individual activity and that mathematics learned in school has little relevance or is not related at all to the real world (Schoenfeld, 1992, pp. 359-360). The students' beliefs may be influenced by their perception about mathematics in the real world. They do not recognize the connection between school mathematics and mathematics in real world.

Mathematics education in school often emphasizes just the procedural knowledge or the 'how' to do a certain way and does not emphasize the meaning and is less focused on the 'why' it is done this way. As the result, it does not encourage students to use intuition in learning. Mathematical intuition is similar to sensory perception in some respects and different in other respects (Chudnoff, 2016). The similarity among others is that they both need interaction with socio-cultural environment. From this interaction, students develop their perception about space and time in line with their intuition of mathematics. The teacher cannot disregard this issue and have to use it in the teaching and learning of mathematics to be more helpful for them. 
There are still many schools in Indonesia that teach mathematics as a discipline, separated from the real world perspective. Junior high school students have studied formal mathematics at least since they have begun the primary school, so how good is their perception of mathematics in real world? Borobudur Temple is known by students, but do they have positive perception about it as a mathematical model? Do they have positive perception about Borobudur Temple as a source of learning for school mathematics?

\section{Aim of the Study}

The aim of this study is to describe student's perception of Borobudur Temple as a mathematic learning resource. Perception is the belief or opinion based on how things seem to the individual through the physical senses and is influenced by experience and prior knowledge. This study focuses on the perception of the cultural artefact as mathematics models and sources for the learning of mathematics at school. This study involved junior high school students as they have attended formal education for at least six to seven years. Students were taken from schools surrounding Borobudur Temple, building perceptions require students to have interaction and experience with the object.

\section{Context and Methodology}

This study used a questionnaire to collect students' perceptions about Borobudur Temple as mathematics learning resources. An exploratory descriptive associative approach was used to explore the position of the variables and the relationship between one variable with another.

\section{Places}

The study took place at SMP Negeri 1 Borobudur and SMP Muhammadiyah Borobudur on April 2015. These schools are located near to the temple.

\section{Participants}

A total of 313 students were the subjects of the study. They consisted of 218 Grade 7 students from SMP Negeri 1 Borobudur and 95 Grade 7 students from SMP Muhammadiyah Borobudur.

\section{Instrument}

The data were collected using questionnaire with Likert scale 1 to 4 with scoring: (1) disagree, (2) neutral, (3) agree, and (4) strongly agree. It is acknowledged that by not having equal positive and negative responses as well as a neutral response places limitations on the data and may operate to produce a positive bias. 
At first, the questionnaire was developed based on two main focuses: (1) Borobudur Temple is a mathematical object [11 items] and (2) utilization of Borobudur Temple as learning source of school mathematics [3 items].

In order to obtain a valid and reliable instrument, two mathematics teachers of junior high school and one teacher trainer from PPPPTK Matematika were involved. A readability test was carried out with 5 students of Grade 7. The statistical analysis used was exploratory factor analysis to determine the items which were not valid. These factors will describe the students' perception on Borobudur Temple.

\section{Findings and Discussion}

\section{Results of Exploratory Factor Analysis}

Students were asked to rate their agreement to each item statement on the instrument "Borobudur Temple as Mathematics Learning Resource". A total 313 students have completed the questionnaire and returned it to the researcher. The results of exploratory factor analysis are as follows.

Table 1.

KMO and Bartlett's Test

\begin{tabular}{llr}
\hline Kaiser-Meyer-Olkin Measure of Sampling Adequacy. & 0,860 \\
\hline Bartlett's Test of Sphericity & Approx. Chi-Square & $1,038 \mathrm{E} 3$ \\
\cline { 2 - 3 } & df & 91 \\
\cline { 2 - 3 } & Sig. & 0,000 \\
\hline
\end{tabular}

The KMO is 0,86 which mean the number of the sample is sufficient and Bartlett's test $\operatorname{sig}<0,05$, then the matrix is not an identity matrix.

\section{Table 2.}

Total Variance Explained

\begin{tabular}{lll}
\hline \multirow{2}{*}{ Component } & \multicolumn{2}{l}{ Initial Eigenvalues } \\
\cline { 2 - 3 } 1 & Total & Cumulative \\
\cline { 2 - 3 } & 4,459 & $31,853 \%$ \\
\hline 2 & 1,368 & $41,623 \%$ \\
\hline 3 & 1,113 & $49,572 \%$ \\
\hline
\end{tabular}

From 14 components, there are three components with eigenvalue $>1$ and these 3 component can explain about $49,572 \%$ of students' perception. 
Table 3.

Rotated Component Matrix

\begin{tabular}{|c|c|c|c|}
\hline \multirow{2}{*}{$\begin{array}{l}\text { No } \\
\text { Items }\end{array}$} & \multicolumn{3}{|l|}{ Component } \\
\hline & 1 & 2 & 3 \\
\hline 1 & ,799 & ,137 &,- 106 \\
\hline 2 & ,333 & ,402 & ,339 \\
\hline 3 &,- 344 & ,334 & ,544 \\
\hline 4 & ,492 & ,473 & , 107 \\
\hline 5 & ,542 & ,148 & ,321 \\
\hline 6 & ,339 & ,215 & ,526 \\
\hline 7 & ,087 &,- 063 & ,752 \\
\hline 8 & , 196 & ,362 & ,377 \\
\hline 9 & ,528 & ,133 & ,438 \\
\hline 10 & 647 & ,127 & , 109 \\
\hline 11 & 610 & ,368 & ,142 \\
\hline 12 & ,246 & 668 & ,168 \\
\hline 13 & , 173 & ,777 & ,036 \\
\hline 14 & ,073 &, 701 & 076 \\
\hline
\end{tabular}

There are no item with loading factor $<0,3$ which means that all items are valid. Three factors were obtained from rotated component matrix, namely: (1) Borobudur Temple is a geometry model [6 items], (2) Borobudur Temple can be used as mathematic learning source at school [4 items], and (3) learning mathematics from Borobudur Temple is helpful for students [4 items].

\section{Results of Descriptive Statistics Analysis}

Table 4.

Cronbach Alpha, Average Item Mean, Average Standard Deviation Scores of Each Factors (N=313)

\begin{tabular}{|c|l|l|l|l|}
\hline Factor & Items & Means & $\begin{array}{l}\text { Standard } \\
\text { Deviation }\end{array}$ & \multirow{2}{*}{ Cronbach $\alpha$} \\
\cline { 1 - 4 } 1. Geometry Model & $1,4,5,9,10,11$ & 3,03 & 0,482 & \multirow{2}{*}{0,8204} \\
\cline { 1 - 4 } 2. Mathematics Learning Source & $2,12,13,14$ & 2,95 & 0,549 & \\
\cline { 1 - 3 } 3. Helpful for Student & $3,6,7,8$ & 2,82 & 0,495 & \\
\hline
\end{tabular}

The average items mean for Factor 1 'Borobudur Temple is a geometry model' is 3,03. It means that the average students 'Agree' for this statement. The average items mean for Factor 2 'Borobudur Temple can be used as mathematic learning source at school' is 2,95 and it is approaching score 3. It means that the average students 'Agree' with this statement. The average items mean for the last factor 'learning mathematics from Borobudur Temple is helpful for students' is 2,82 and it is approaching score 3. It indicates that the average students also 'Agree' with the statement.

The highest mean score was attained for Factor 1. Students have perception that Borobudur Temple is a geometrical model. They agree that mathematics model such as cube, 
cuboid, pyramid, and prism can be found at the temple. They also agree that geometric pattern at the temple and the whole building is a geometrical model.

Students have a positive perception because they can see those models as part of the building. This experience was connected with their knowledge about varied geometry models from school. In accordance with geometry topics they have learned since elementary school until the seventh grade, they were able to identify that some parts of Borobudur Temple are cuboids and prisms.

Students agreed that mathematics identified in Borobudur Temple should be applied in school activities. They agreed that school mathematics topics can be learned from this temple including the comparison of the length, width, area and volume, and pattern of numbers. This positive perception is associated with the perception of student that it is a geometry model, therefore Borobudur Temple can be utilized as a source of learning in school.

The lowest mean score was attained for Factor 3 'Learning mathematics from Borobudur Temple is helpful for students'. These results could be affected by the condition of the students who have never experienced using Borobudur Temple in the learning of mathematics at school. Their beliefs about learning mathematics are confined to the classroom because that is where they have learned mathematics so far. Students had positive perceptions that the application and practice of mathematics at Borobudur Temple is important to learn because it can generate a sense of pride in their own cultural richness. Mathematical contained in historical sites such as the temple can be lost if it is not taught in schools. Some mathematical topics identified in Borobudur Temple should be included in mathematics curriculum at junior high school.

Students thought that mathematical knowledge can be reached through investigations, this meaningfully mathematics learning is useful for them. By building a mathematical knowledge based on experience of students in everyday life, teachers can encourage students to make the connection between mathematics outside and inside the school in ways that will help student formalized the informal knowledge of mathematics and to learn mathematics more meaningful (Masingila, 2002, p. 30). The practical experience of mathematics in everyday life is useful as a specific context for student, which can be used as a basis to make a connection with the relevant school mathematics. The context of the problems from everyday situation has the advantage of the significance of the issues to be resolved. Students was encouraged to resolve the matter in earnest by using a strategy that may be different with that is learned at school.

It is a challenge for teachers to help students see and find that they have engaged with mathematics in their daily activities. Most students and teachers themselves have the perception 
that mathematics is present in school only through the display of numbers and formulas. Students need to be given the opportunity to do activities in the classroom which are generally carried out in the culture of their community. Teachers must show them how mathematics is used in everyday life, especially in their culture. Therefore, mathematics must be associated with the real matter for students and mathematics should be viewed as a human activity (Gravemeijer, 1994, p. 82).

Teachers should be able to understand the disposition of students and determine the scope of the dispositions of students that include three dimensions namely student perspective on the importance of mathematics, student's motivation to engage in the task of mathematics, and perceptions of the students (self-perception) about their own mathematics abilities (Campbell, et al., 2014, p. 429). Students have a positive perception of the existence of mathematics in the real world based on their intuition. They can learn mathematics at an intuitive level long before the reflective level (Skemp, 1971, p. 66). This carries important implications in the learning of mathematics.

\section{Conclusion and Recommendation}

Based on findings of the study and the limitations noted in the methodology, we can conclude that this group of junior high school students have positive perceptions about Borobudur Temple as learning source for school mathematics. Students agreed that Borobudur Temple is a geometrical model, it can be used as a source of learning mathematics school, and will be beneficial for them. This positive perception comes from students whose school is located near Borobudur Temple, meaning that the interaction and experience are important in their learning. These perceptions bring implications for their teachers, they should be able to draw on intuition and experience of students when presenting the material in order to make it more meaningful. Therefore, teachers can design learning activities that take advantage of Borobudur Temple as mathematical objects.

\section{References}

Patricia F. Campbell, Masako Nishio, Toni M. Smith, Lawrence M. Clark, Darcy L. Conant, Amber H. Rust, . . . Youyoung Choi. (2014). The relationship between teachers' mathematical content and pedagogical knowledge, teachers' perceptions, and student achievement. Journal for Research in Mathematics Education, 45(4), 419-459. https://doi.org/10.5951/jresematheduc.45.4.0419

Chudnoff, E. (n.d.). Intuition in mathematics. Retrieved October 12, 2016, from http://www.as.miami.edu/personal/echudnoff/Intuition\%20in\%20Mathematics.pdf.

D'Ambrosio, U. (2006). The program ethnomathematics: A theoretical basis of the dynamics of intra-cultural encounters. The Journal of Mathematics and Culture, 1(1), 1-7. 
Francois, K., \& Van Kerkhove, B. (2010). Ethnomathematics and the philosophy of mathematics (Education). In B. Lowe, \& T. Muller (Eds.). PhiMSAMP. Philosophy of mathematics: Sociological aspect and mathematical practice (pp. 121-154). London: College Publication.

Gerdes, P. (2014). Ethnomathematics and education in Africa. Boane: ISTEG.

Gravemeijer, K. P. E. (1994). Developing realistic mathematics education. Utrecht: CD $\beta$ Press.

Masingila, J.O. (1993). Learning from mathematics practice in out-of-school situations. Journal for the Learning of Mathematics, 13(2), 18-22.

Masingila, J.O. (2002). Examining students' perception of their everyday mathematics practice. Journal for Research in Mathematics Education, 11, 30-39.

Parmono, A. (1988). Some architectural design principles of temples in Java: A study through the building projection on the relief of Borobudur temple. Yogyakarta: Gadjah Mada University Press.

Prediger, S. (2004). Intercultural perspectives on mathematics learning - Developing a theoretical framework. International Journal of Science and Mathematics Education, 2(3), 377-406.

Rosa, M., \& Orey, D.C. (2013). Culturally relevant pedagogy an ethnomathematical approach. Journal of Mathematics \& Culture, 7(1), 74-97.

Schoenfeld. (1992). Learning to think mathematically: Problem solving, metacognition, and sense making in mathematics. In G, Douglas A (Eds.), Handbook of research on mathematics teaching and learning (pp. 334-366). New York: Macmillan Publishing Company.

Skemp, R. R. (1971). The psychology of learning mathematics. New York: Penguin Books Ltd.

Soetarno (1988). Aneka candi kuno di Indonesia. Semarang: Penerbit Dahara Prize.

Situngkir, H. (2010). Borobudur was built algorithmically. Retrieved November 24, 2015 , from: http://papers.ssrn.com/sol3/papers.cfm?abstract_id=1672522

Tall, D. (2013). Integrating history, technology and education in mathematics. Retrieved February 2014, from http://homepages.warwick.ac.uk/staff/David.Tall/pdfs/dot2013dhtem-plenary.pdf 
Southeast Asian Mathematics Education Journal 2017, Vol. 7 No. 1 